\title{
Extração e Quantificação de Compostos Bioativos a partir de Resíduos de Processamento de Frutas Vermelhas
}

\author{
Julian Martinez (PQ), Ana Paula F. Machado (PG), Ana Luiza D. Pereira (IC) \\ Resumo
}

Visando o aproveitamento de subprodutos do processamento de pequenas frutas vermelhas, o objetivo desse trabalho foi obter extratos ricos em compostos com caráter antioxidante, como antocianinas, empregando técnica de extração com líquido pressurizado (PLE); a técnica de extração Soxhlet e por Banho Ultrassônico com o intuito de comparar os resultados obtidos. A fim de melhorar a extração PLE, foi utilizado o ultrassom como pré-tratamento da amostra, seguido da PLE (Ultrassom-PLE). Os extratos obtidos foram avaliados em termos do teor de compostos fenólicos totais, teor de antocianinas monoméricas e da atividade antioxidante (AA), por meio dos métodos DPPH, ABTS e FRAP.

\section{Palavras Chave: Inserir : frutas vermelhas, antioxidantes, PLE.}

\section{Introdução}

O processamento de alimentos de origem vegetal gera grande quantidade de subprodutos conhecidos por serem fontes ricas em compostos bioativos ${ }^{1}$. O aproveitamento dos subprodutos pode resultar em novas alternativas empresariais e minimizar o acúmulo desses resíduos ${ }^{2}$. Pequenas frutas vermelhas, como amora-preta, mirtilo e grumixama, são fontes valiosas de compostos bioativos ${ }^{1}$, principalmente em antocianinas. As antocianinas têm despertado grande interesse devido à ampla gama de atividades biológicas, incluindo antioxidante, antiinflamatória ${ }^{2}$. A recuperação de compostos fitoquímicos a partir de resíduos pode ser feita pela técnica de extração por líquido pressurizado (PLE) tecnologia limpa e rápida, com a possibilidade de ajuste dos parâmetros visando melhor a solubilidade dos analitos no solvente e a cinética de dessorção a partir de matrizes ${ }^{1}$. Recentes estudos ${ }^{3}$ têm mostrado que a utilização da extração a alta pressão/temperatura assistida por ultrassom melhora significativamente a eficiência e o rendimento da extração. Isso ocorre porque o ultrassom tem um efeito mecânico que permite uma maior penetração dos solventes na matriz e aumenta a superfície de contato entre o sólido e o solvente. Além disso, a ocorrência de cavitação leva à ruptura celular e isto pode aumentar a velocidade de extração ${ }^{3}$.

Resultados e Discussão

Os resultados das análises do teor de fenólicos totais e antocianinas monoméricas indicaram que a PLE e Ultrassom-PLE, de forma geral, aumentaram significativamente a extração de compostos fenólicos, em relação aos outros métodos. Quanto à analise da AA, foi possível notar melhores resultados nos extratos obtidos pela Ultrassom-PLE, quando comparados aos outros métodos (tabela).

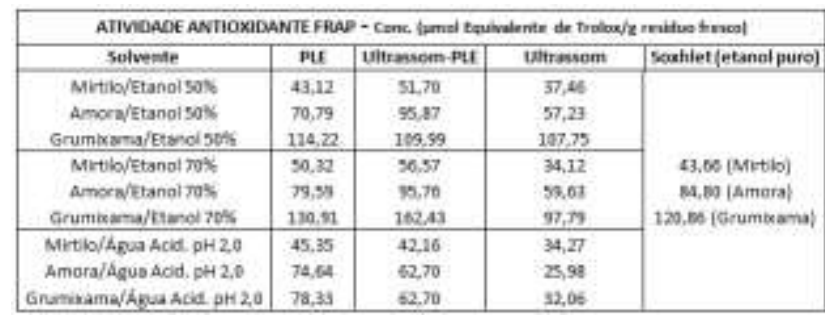

É importante ressaltar que, nas extrações com água acidificada a pH 2.0 como solvente extrator, os resultados de teor de fenólicos totais, antocianinas monoméricas e AA foram bem menores em relação aos outros solventes usados. E comparando as misturas etanol/água, o solvente extrator mais eficiente foi etanol $70 \%$.

\section{Conclusões}

Diante dos resultados obtidos, pode-se concluir que a PLE e, principalmente, a Ultrassom-PLE, são técnicas que proporcionam melhor extração e rendimento comparado às técnicas convencionais.

\section{Agradecimentos}

Agradeço ao PIBIC/CNPQ pelo apoio financeiro, ao orientador Julian Martinez e à doutoranda Ana Paula Machado pelo auxílio durante a elaboração dos experimentos e análise dos resultados.

\footnotetext{
WIJNGAARD, H. et al. Techniquesto extractbioactivecompoundsfromfoodby-productsofplant origin. FoodResearchInternational, v. 46, n. 2, p. 505-513, 2012.

MACHADO, A. P. M. Extração de compostos bioativos do bagaço da amora-preta (Rubus spp.) utilizando líquidos pressurizados. Dissertação de Mestrado. Departamento de Engenharia de Alimentos, Universidade Estadual de Campinas, Campinas, 2014. Liazid, Ali; Barbero, Gerardo F; Azaroual, Latifa; Palma Miguel.Stability of Anthocyanins from Red Grape Skins under Pressurized Liquid Extraction and Ultrasound-Assisted Extraction Conditions. Molecules 2014, 19, 21034-21043
} 